\title{
Síndrome de disgenesia de conductos mullerianos: Agenesia de cuello y $2 / 3$ superiores de vagina
}

\author{
Gustavo Gómez T.*
}

El síndrome de Disgenesia de los Conductos Mullerianos tiene diferentes manifestaciones de acuerdo a la porción de los conductos afectados. La posibilidad o no de fertilidad, incide en el enfoque diagnóstico, el manejo y el pronóstico. La presencia o no de un útero cavitado con trompas permeables, con la disponibilidad de las actuales técnicas de reproducción asistida, es básico en el diagnóstico y ha cambiado el enfoque terapéutico. En el presente artículo describimos una técnica quirúrgica para esos casos, acorde a la época de auge en técnicas de reproducción asistida que vivimos.

\section{Presentación de un caso}

Paciente de 21 años de edad. Consulta porque no ha menstruado aún, y además sufre de cólicos abdominales mensuales, que se han incrementado a través del tiempo. Niega relaciones sexuales. No hay antecedentes de importancia en la familia. No hay antecedentes personales de importancia.

$\mathrm{Al}$ examen físico se encuentra una paciente mestiza de 1.55 de estatura con características sexuales secundarias bien desarrolladas. Mamas tanner IV, vello púbico tanner IV.

Los genitales externos femeninos son normales, introito normal, vagina termina en fondo de saco ciego de $0.5 \mathrm{~cm}$ de profundidad. TR. Utero ligeramente aumentado de tamaño, anexos no palpables, no masas.

Se practicaron los siguientes exámenes de laboratorio:

FSH. 3.5, LH. 7.2 T. $42 \mathrm{mg} / \mathrm{dl}$. normales en nuestro laboratorio. El cariotipo fue 46XX. Urografía excretora fue normal, hemograma, parcial de orina, glicemia NU, creatinina dentro de rangos normales.

Se realizó ecografía pélvica que mostró útero cavitado de tamaño normal con contenido líquido en su interior y ovarios normales. Laparoscopia: mostró cuerpo uterino y trompas de falopio normales, ovarios normales, cuerpo lúteo presente. Signos de sangrado antiguo en cavidad. No hay implantes de endometriosis. En la punción de útero y aspiración se obtuvo sangre espesa.

DX. Disgenesia de conductos Mullerianos

A. Agenesia de cérvix $2 / 3$ superiores de vagina

B. Utero cavitado con trompas normales

\footnotetext{
* Profesor Titular Departamento de Ginecología y Obstetricia. Facultad de Salud. Universidad del Valle.
}

Se dispone tratamiento quirúrgico en dos fases, en el mismo acto quirúrgico.

1. Laparotomía (Figura 1). Se hace prueba de permeabilidad retrógrada con azul de metileno y se comprueba permeabilidad tubárica bilateral, previa aspiración de contenido uterino.

Figura 1

DIAGRAMA DE HALLAZGOS

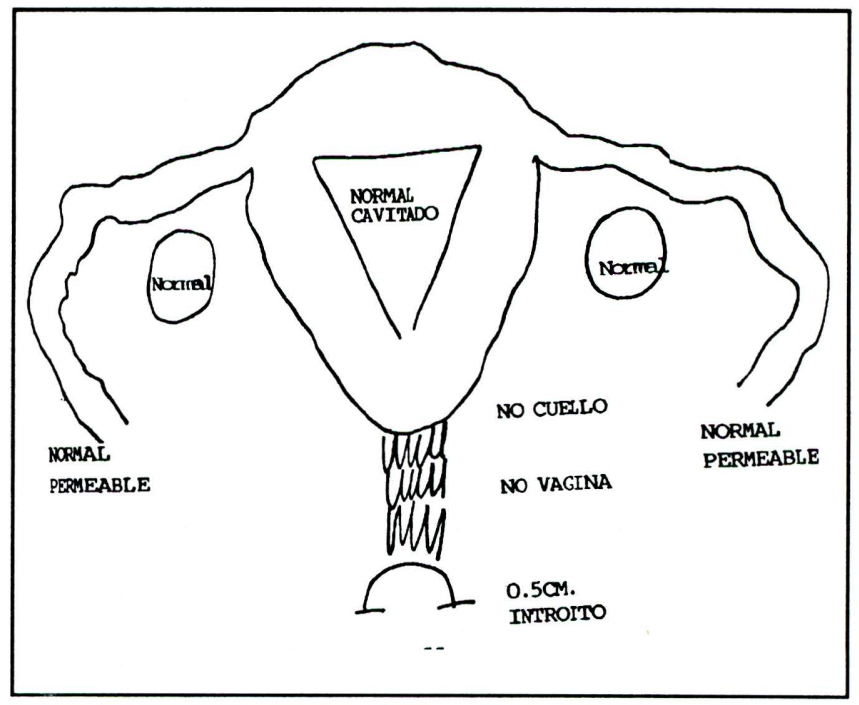

\section{Técnica quirúrgica}

a. Se diseca peritoneo en pliegue vesico-uterino y se rechaza vejiga.

b. Se expone extremo anterior de útero.

c. Se busca sitio central de menor resistencia y se práctica uterostomía.

d. Se dilata con dilatadores Hegar (hasta No. 5).

e. Se introduce sonda de Folley No. 8, se infla $5 \mathrm{cc}$ el balón y se deja intrauterino (Figura 2).

2. Neovagina (Figura 3 )

a. Inserción de sonda vesical para dejar a permanencia

b. Incisión en media línea con convexidad inferior de 2 $\mathrm{cm}$. de longitud en mucosa de fondo ciego de vagina.

c. Disección con tijera y disección roma, con orientación antero-posterior y superoinferior, con protección y guía con dedo en recto con doble guante.

d. Se mide el molde de balso de una longitud de $+12 \mathrm{~cm}$. 
Figura 2

«NEOCERVIX» CON SONDA FOLLEY EN UTERO

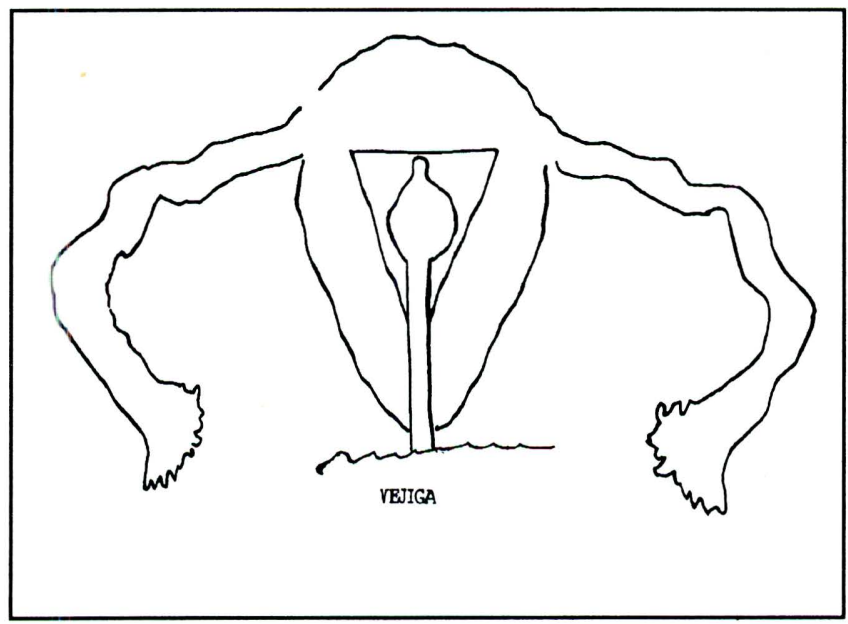

Se practica neostomía en región anterior de útero y se introduce sonda Folley $\mathrm{N}^{\circ} 18$.

Figura 3

NEOVAGINA CON SONDA FOLLEY COMUNICADA

\section{AL EXTERIOR}

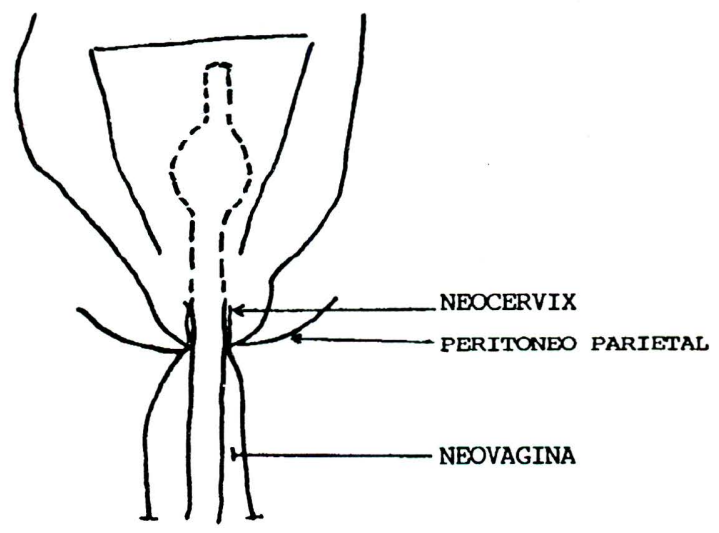

Figura 4

SUTURA DE FONDO DE NEOVAGINA ALREDEDOR DE NEOCUELLO

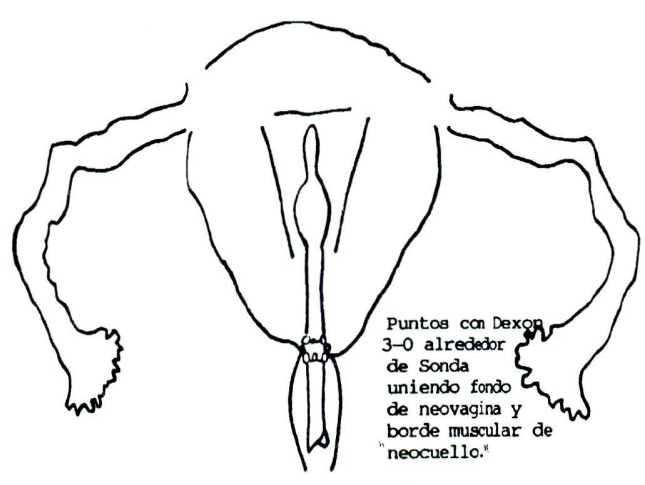

Se hace neovagina. Se abre fondo de peritoneo parietal y se abre para poner segmento distal de sonda.

- Se practica sutura con puntos separados de Dexon 3-0. e. Incisión en peritoneo parietal en fondo de neovagina bajo visión directa abdominal se pasa parte distal de sonda de Folley intrauterina.

f. Se suturan bordes de neovagina a «neocuello» con puntos separados (Figura 4) de dexon 3-0.

g. Toma de injertos de piel de región postero-interno de muslo y glúteo con dermatomo eléctrico de Paget.

h. Se distiende el injerto. Se coloca alrededor de molde con cara externa en contacto con él, que a su vez está recubierto con doble condón entre los cuales pasa la sonda de folley intrauterina (Figura 5).

Figura 5

ESTADO FINAL DE LA CIRUGIA

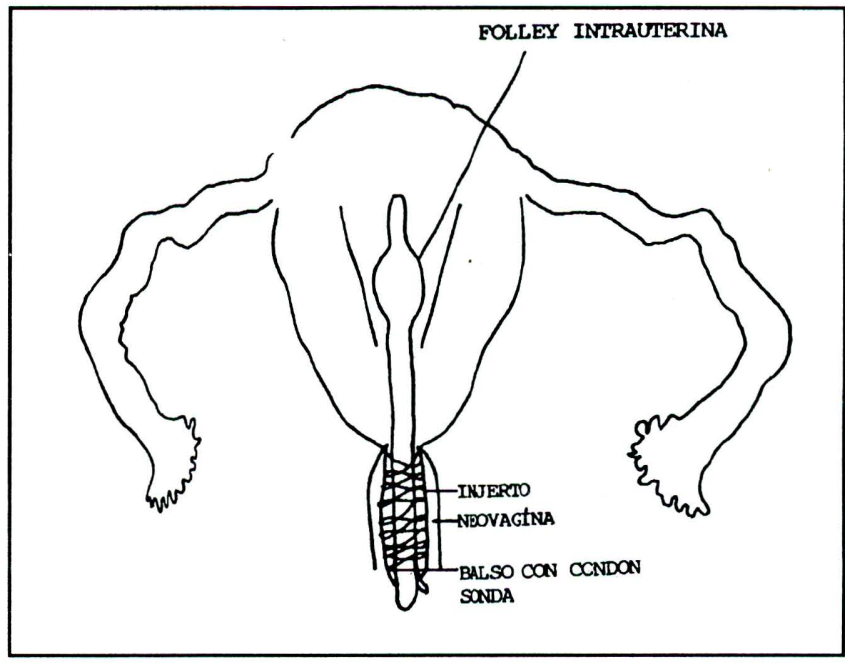

El molde de balso ha sido recubierto con un condón. Luego viene la sonda, recubierta por otro condón, el cual se recubre con el injerto de piel.

i. Se toma segundo injerto en otro miembro inferior, más delgado para colocar en sitio de toma de injerto inicial (con el fin de que la cicatriz sea más estética y reepitelice mejor).

j. Se introduce en neovagina molde cubierto con el injerto.

k. Se fija con un guayuco hecho con apósitos de gasa que se fijan a un cinturón firme alrededor de la cintura.

Post-operatorio. Por ocho días la paciente tiene el molde in situ las 24 horas y sonda vesical a permanencia durante igual tiempo. El sitio del injerto se descubre a los 3 días y se hacen curaciones diarias con limpieza y toques de mercurio cromo.

Después de ocho días hasta un mes, el molde se coloca dos horas a mañana y tarde, permanente por la noche. La sonda intrauterina se retira a los 30 días.

A los dos meses de la cirugía la vagina se destiende normalmente, los injertos de los muslos están sanos y ya se ha presentado la menstruación durante 4 días 5 paños al día.

\section{Comentarios}

El síndrome de Disgenesia de los Conductos Mullerianos, se manifiesta en una amplia gama de defectos de genitales internos y externos. Va desde ausencia de útero, trompas y $2 /$ 3 superiores de vagina a cualquier otra forma de presentación (1). 
El diagnóstico diferencial se hace principalmente con el Síndrome de Feminización Testicular. En casos obstructivos la principal causa de consulta es el dolor pélvico (2). En laparoscopias hechas por dolor pélvico en adolescentes, el $8 \%$ tenían anomalías con obstrucción del flujo menstrual (3). La presencia de gónadas masculinas usualmente en el canal inguinal con fenotipo femenino, agenesia de vagina cariotipo $\mathrm{XY}$ y testosterona en niveles masculinos, hacen el diagnóstico de feminización testicular.

En la Disgenesia Mulleriana las gónadas son femeninas, el cariotipo XX y los niveles de testosterona en rangos femeninos. La ecografía es necesaria para detectar la presencia de útero y determinar si éste es o no cavitado. La laparoscopia en el caso de ser cavitado con hematometra es importante para observar si hay permeabilidad tubárica y si hay endometriosis secundaria a la menstruación retrógrada. No se encuentra endometriosis en la mayoría de los casos.

Algunos médicos todavía insisten en practicar histerectomía en estas pacientes, conducta que consideramos inadecuada puesto que en la actualidad es mucho lo que en cuanto a fertilidad se refiere y podemos ofrecerle a éstas pacientes. Sólo en el caso de útero cavitado, realizamos en primera instancia la neovagina quirúrgica. En los otros casos insistimos en la dilatación vaginal, con dilatadores de diversos materiales, en pacientes con o sin relaciones sexuales.

En el caso que presentamos la paciente alivia sus cólicos mensuales al poder el flujo menstrual salir al exterior y se le da una seria posibilidad de intentar un embarazo con coito o inseminación artificial. También queda vigente la posibilidad de una fertilización in vitro y transferencia de embriones en un útero por lo demás normal.

La situación de esta paciente no es infrecuente. En el último año hemos realizado 4 correcciones quirúrgicas similares, con resultados satisfactorios en cuanto a menstruaciones normales, alivio total del dolor, sin presentarse aún mujeres en embarazo.

La técnica quirúrgica para neovagina, más ampliamente usada, es la de Mc Indoe (4-5). La combinación de ésta con la comunicación del contenido uterino con el exterior, que llamamos «Neocuello», es una adición importante, cuando, gracias a la popularización de técnicas de reproducción asistida en útero funcional es garantía de un probable embarazo.

\section{BIBLIOGRAFIA}

1. Goldstein D., Pinsonneault O. Obstructing malformations of the uterus and vagina. Fertil Steril 1985; 44: 241.

2. Duarte A. Criptomenorrea. Rev. Col. Obstet. Ginecol. 1989; 40: 313.

3. Goldstein D et al. Laparoscopy in the diagnosis and management of pelvic pain in adolescents. J. Reprod. Med. 1980; 33: 15.
4. McIndoe. The aplication of covity grafting Surgery 1937; 1:535-537.

5. Onatra W., Ortega C., Pérez O. Ausencia congénita de vagina. Rev. Col. Obstet. Ginecol. 1992; 43: 175. 